SECTION 25. Technologies of materials for the light and textile industry.

Klyueva Inna Viktorovna assistant professor, candidate of technical Sciences

Novosibirsk Institute of technology (branch)

Design and Technology Moscow State University

Shelomentseva Olga Evgenevna undergraduate(master student) Novosibirsk Institute of technology (branch) Design and Technology Moscow State University

Savina Natalia Viacheslavovna graduate student

Novosibirsk Institute of technology (branch)

Design and Technology Moscow State University

\title{
THE RANGE OF NURSERIES OF BLOCKS FOR ORTHOPEDIC FOOTWEAR
}

\begin{abstract}
In article division of orthopedic footwear depending on degree of expressiveness of deformation of foot is considered. For design of children's orthopedic footwear different types of blocks are in detail considered, their short characteristic is described, features of blocks considering anthopometrical features of a structure of foot are given. The full scheme displaying elements for transformation of an internal form of children's blocks is provided.
\end{abstract}

Key words: orthopedic children's footwear, block, design, deformation.

\section{АССОРТИМЕНТ ДЕТСКИХ КОЛОДОК ДЛЯ ОРТОПЕДИЧЕСКОЙ ОБУВИ}

Аннотация: В статье рассмотрено разделение ортопедической обуви в зависимости от степени выраженности деформаџии стопы. Для проектирование детской ортопедчческой обуви подробно рассмотрены различные виды колодок, описана их краткая характеристика, приведены особенности колодок учитывающие антропометрические особенности строения стопы. Предоставлена полная схема, отображающая элементы для преобразования внутренней формы детских колодок.

Ключевые слова: ортопедическая детская обувь, колодка, проектирование, деформачия

Целью ортопедии детского возраста является профилактика, устранение деформаций и нарушений функции опорно-двигательного аппарата. Она изучает причины и механизм развития патологических состояний и нарушений функции системы движения, устранение деформаций и восстановление формы и функции опорно-двигательного аппарата достигаются консервативными и хирургическими методами лечения. Ортопедическая обувь является одним из основных инструментов консервативного лечения, следовательно вопросы научнообоснованого проектирования весьма актуальны на сегодняшний день [1,с.95].

Соответствие ортопедической обуви возлагаемым на нее функциям, достигается более тщательным подходом к выбору конструкций верха и низа изделия, а также включением в ее структуру специальных, особой формы и размеров, деталей. 
В зависимости от степени выраженности деформации стопы, ортопедическая обувь подразделяется на малосложную и сложную.

Малосложная ортопедическая обувь предназначена для лиц, имеющих умеренно выраженные деформации нижних конечностей. Обувь выпускается увеличенной полноты (до тринадцатой) по специальным ортопедическим колодкам.

Также возможен серийный выпуск такой обуви. В этом случае под малосложной ортопедической следует понимать такую обувь, внутренняя форма которой унифицирована и разработана с учетом анатомических изменений нижних конечностей при патологиях, на которые она рассчитана. При этом индивидуальный подход к лечению обеспечивается за счет варьирования профиля вкладной ортопедической стельки, параметры которой учитываются при проектировании внутренней формы обуви. Таким образом вкладная профилированная ортопедическая стелька является не отдельным вкладным приспособлением, а специальной деталью разрабатываемой малосложной ортопедической обуви.

Сложная ортопедическая обувь, предназначена для лиц, имеющих выраженные деформации и дефекты стопы. К сложной относится обувь, имеющая не менее двух специальных ортопедических деталей или косок для компенсации укорочения от 30 мм и более. Эта обувь выпускается как по стандартным колодкам, так и по гипсовым слепкам [2,c.244]. Обувь содержит специальные детали, корригирующие положение стопы: жесткие союзки, берцы, выкладку свода, пронатор, скошенные или удлиненные каблуки и т.д.

Сложная ортопедическая обувь характеризуется специальной конструкцией верха и низа. Ее изготовление практически всегда осуществляется индивидуально.

Для проектирования детской ортопедической обуви существуют несколько видов колодок. На рис. 1 представлена берцовая колодка для формования жесткого высокого задника или корсета к нижней трети голени.

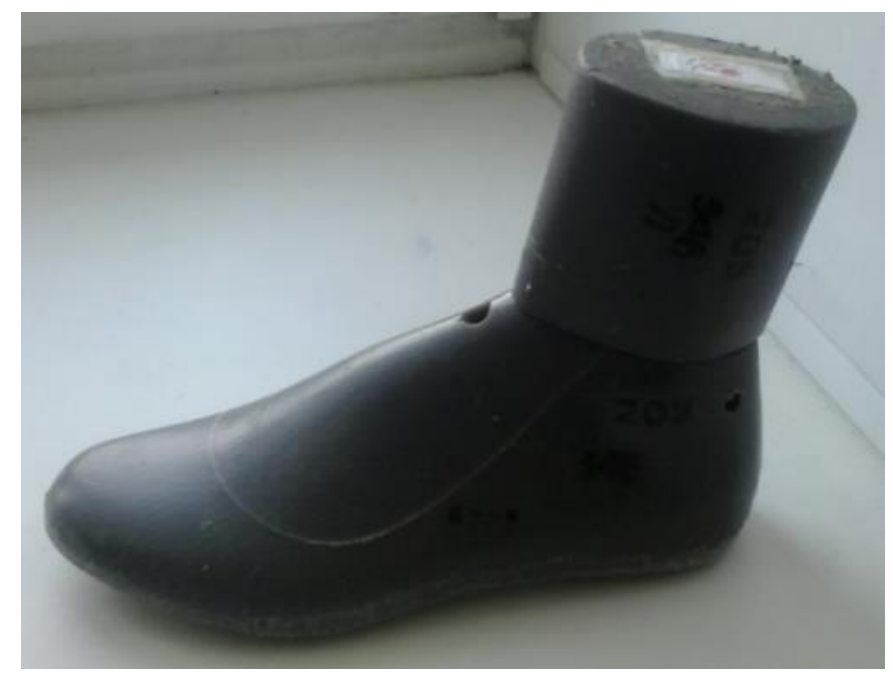

\section{Рисунок 1- Берцовая колодка.}

На рис. 2 представлена берцовая колодка с войлочной личиной для увеличения внутриобувного пространства. Применение такой личинки обусловлено параметрами стопы ребенка. 


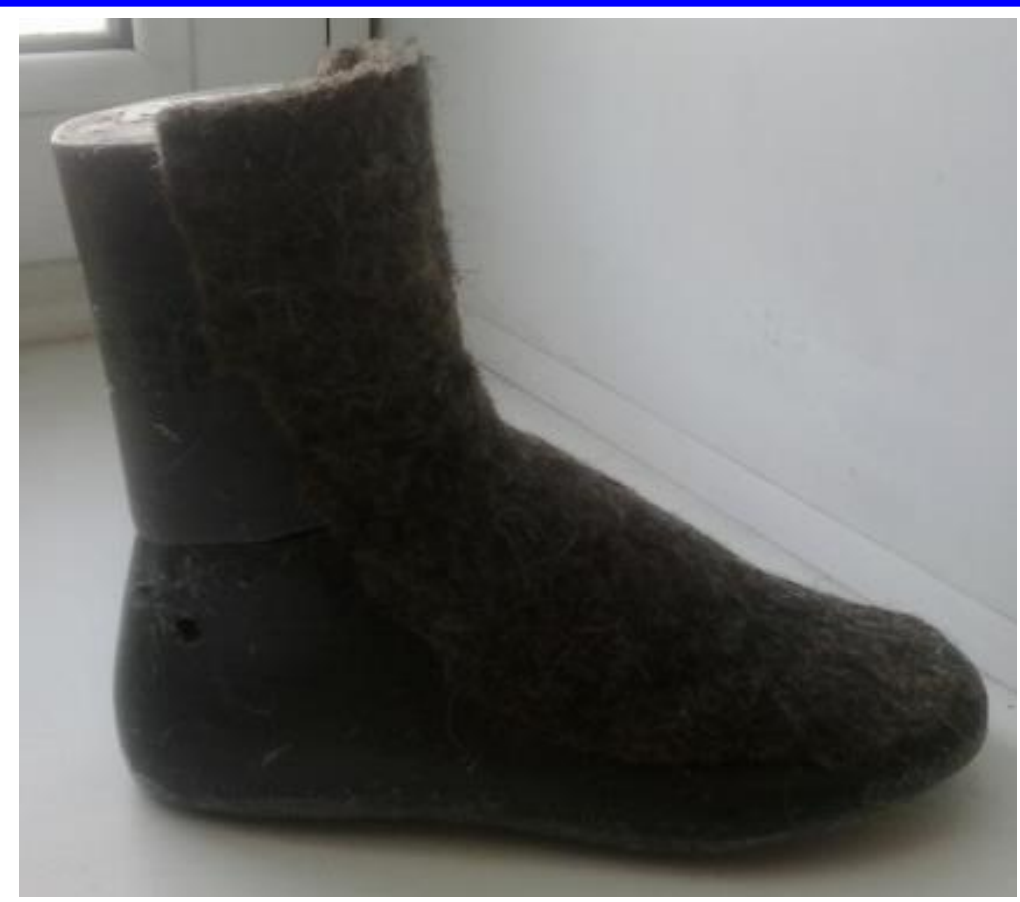

Рисунок 2- Берцовая колодка с войлочной личиной.

На рис. 3 представлена колодка с войлочной личиной - для увеличения внутриобувного пространства и увеличения косого взъема. Кожаная личина предназначена для увеличения опорной поверхности стопы, расширения стельки. Колодка является аппаратной, для изготовления на этой колодке ботинка с жесткими берцами, специально выточена и прикреплена к опорной площадке трубка, копирующая нижнюю треть голени

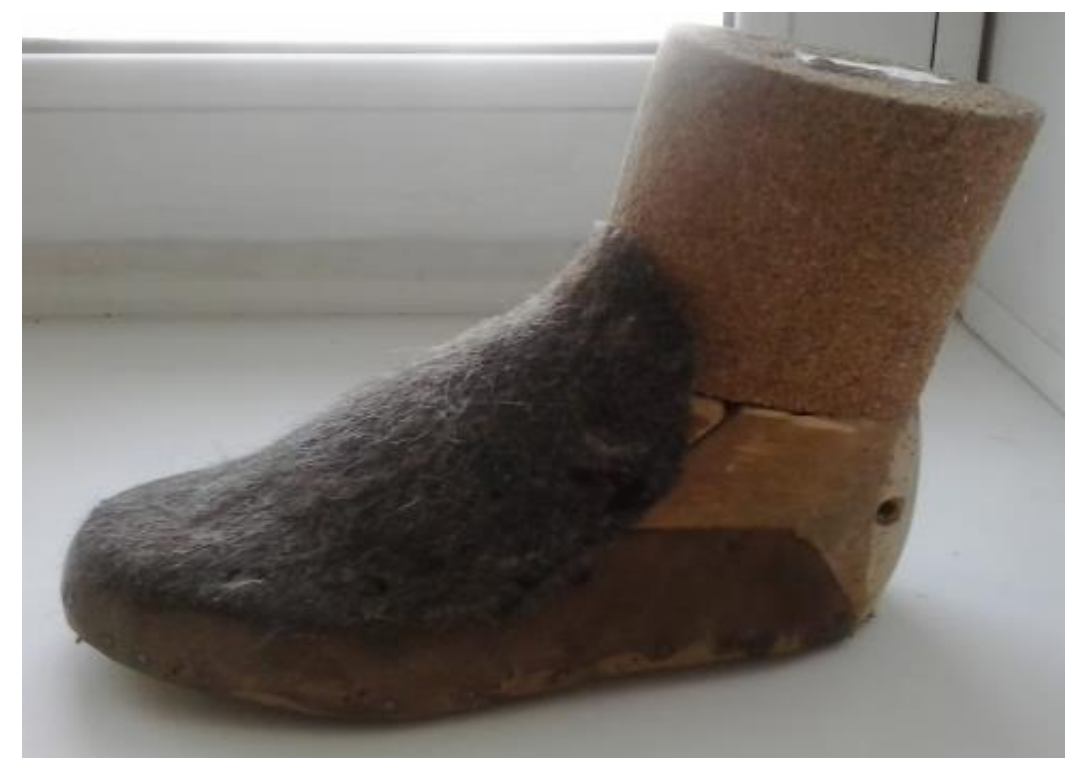

Рисунок 3 - Колодка на паралитическую стопу (на основе аппаратной).

Таким образом, конструктивные элементы для преобразования внутренней формы детских колодок можно представить в виде схемы (рис. 4) . 


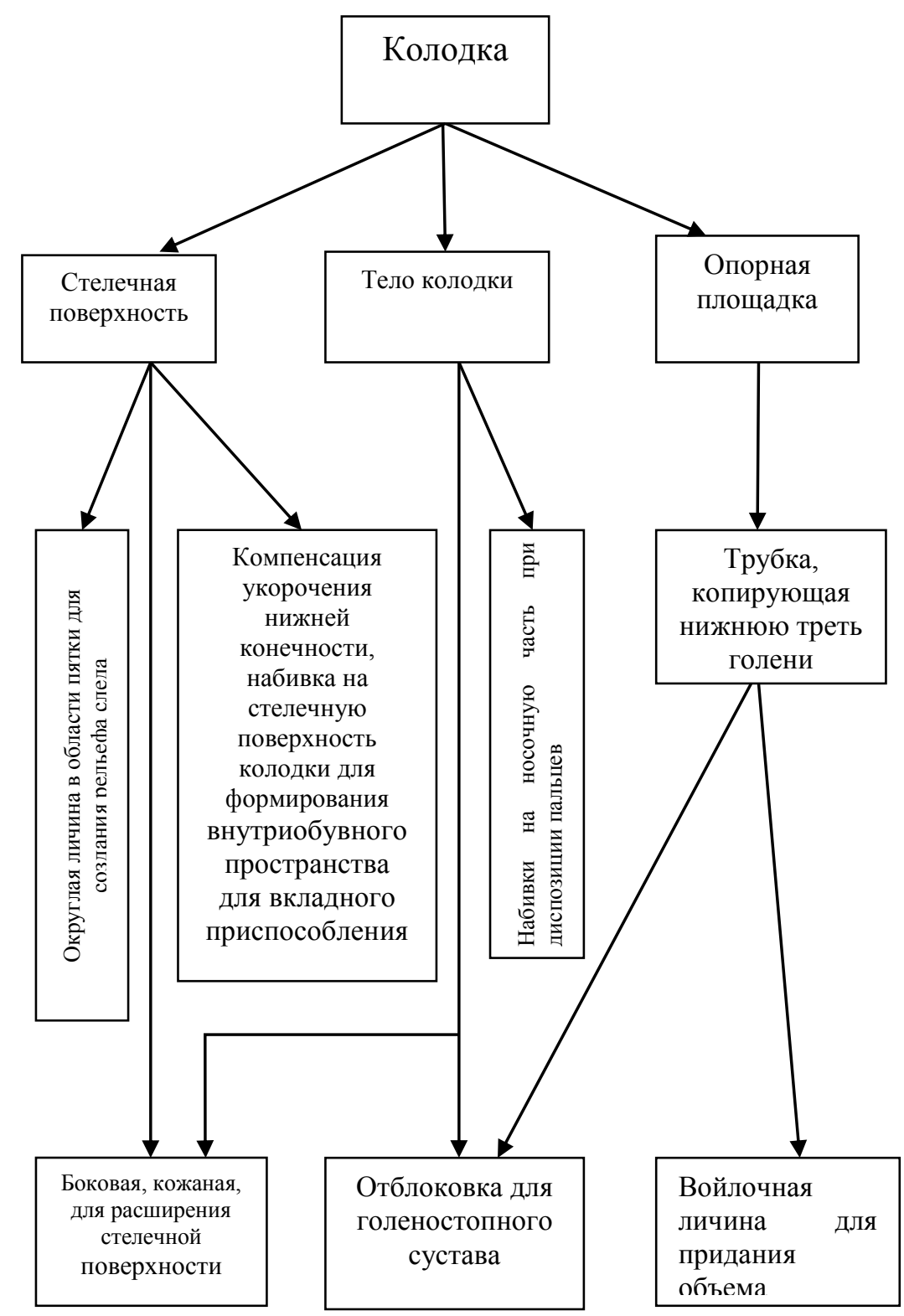

\section{Рисунок 4- Классификация конструктивных элементов по месту расположения на колодке.}

Данная схема предлагается авторами для применения в технологическом процессе производства ортопедической обуви на протезно-ортопедическом предприятии для преобразования конструктивных элементов внутренней формы детских колодок.

\section{Список литературы:}

1. Савина Н.В., Клюева И.В., Бекк Н.В. Социальная и психологическая адаптация детей инвалидов, и их интеграция в общество. [Текст]/Н.В. Савина, И.В. Клюева, Н.В. Бекк// Theoretical\&Applied Science.- 2013.-№ 7(3).- C.95-98.

2. Бекк Н.В., Клюева И.В., Тихонова Н.В. Подгоночные колодки в структуре технологической подготовки ортопедического производства. Том 16. [Текст]/ Н.В. Бекк, И.В. Клюева, Н.В. Тихонова// Вестник Казанского технологического университета.- 2013.- №1 .- С.243-245. 